\title{
Secretary's Advisory Committee on Heritable Disorders in Newborns and Children response to the President's Council on Bioethics report: The changing moral focus of newborn screening
}

\author{
Tracy L. Trotter, $M D^{1}$, Alan R. Fleischman, $M D^{2}$, R. Rodney Howell, $M D^{3}$, \\ and Michele Lloyd-Puryear, MD, PhD ${ }^{4}$, for the Secretary's Advisory Committee on Heritable \\ Disorders in Newborns and Children
}

$T^{\mathrm{s}}$ he following is a commentary from the Secretary's Advisory Committee on Heritable Disorders in Newborns and Children (SACHDNC) concerning the President's Council on Bioethics' (Council) (2001-2009; disbanded in February 2009) report on newborn screening entitled "The Changing Moral Focus of Newborn Screening." 1

The SACHDNC provides advice and recommendations to the Secretary of the federal Department of Health and Human Services (HHS) on matters concerning screening infants and children for inherited disorders. The SACHDNC's charge is to advise and guide the Secretary, HHS, regarding the most appropriate application of childhood and universal newborn screening tests, technologies, policies, guidelines, and programs for effectively reducing morbidity and mortality in newborns and children. In addition, SACHDNC is charged to make systematic evidence-based and peer-reviewed recommendations that include the heritable disorders, which have the potential to affect public health significantly, for which all newborns should be screened, including secondary conditions that may be identified as a result of the laboratory methods used for screening. As of September 2010, SACHDNC has considered nominations for screening newborns for nine conditions. Formal reviews by the Evidence Review Workgroup were conducted on six conditions; the remaining were considered not ready for evidence reviews. Two conditions were recommended to be added to the SACHDNC's Recommended Uniform Screening Panel: Severe Combined Immunodeficiency (SCID) and Critical Congenital Cyanotic Heart Disease. The Secretary, HHS, accepted the addition of SCID to the panel; the Secretary's decision for Critical Congenital Cyanotic Heart Disease is pending.

From the ${ }^{1}$ San Ramon Valley Primary Care Medical Group, San Ramon, California; ${ }^{2}$ March of Dimes Foundation, White Plains, New York; ${ }^{3}$ Miller School of Medicine, University of Miami, Miami, Florida; and ${ }^{4}$ Department of Health and Human Services, Health Resources and Services Administration, Rockville, Maryland.

Michele Lloyd-Puryear, MD, PhD, Secretary's Advisory Committee on Heritable Disorders in Newborns and Children, Health Resources and Services Administration, Room 18A-19, Rockville, MD 20857. E-mail: mpuryear@hrsa.gov.

The opinions and assertions contained herein are the views of the Secretary's Advisory Committee on Heritable Disorders in Newborns and Children and are not to be construed as official or as reflecting the views of the Department of Health and Human Services.

Disclosure: The authors declare no conflict of interest.

Submitted for publication November 19, 2010.

Accepted for publication January 14, 2011

Published online ahead of print March 14, 2011

DOI: 10.1097/GIM.0b013e318210655d
Newborn screening is an essential preventive public health program that provides early identification of rare genetic, metabolic, hormonal, and functional disorders among infants and follow-up care for those affected. Without treatment, the screened-for disorders can result in devastating health consequences and in some cases, death. ${ }^{2}$ Newborn screening is not merely testing but a process that screens virtually all newborns in the United States for disorders for which there is documented benefit to the infant from early detection and for which there is a reliable screening test that is feasible in a public health setting. Newborn screening has evolved into an organized, systematic approach to assure that every infant identified as screen positive will undergo diagnostic evaluation and, when necessary, treatment and management. The decision process for determining each state's screening panel is a state responsibility. However, until the establishment of SACHDNC, there was little uniformity in the screening panels in the various state programs.

From 2001 until 2009, the President's Council on Bioethics produced a series of monographs and reports developed to advise the President and the public on ethical issues related to advances in biomedical science and technology. The Council members included the following disciplines: economics, ethics, law, medicine, philosophy, political science, and psychology.

The aim of the Council's report on newborn screening was to "foster public awareness of the practice of newborn screening, the ethical principles that have guided it until now and the ethical problems posed by its current and future expansion." As noted in the introduction, the report was written to answer the overarching question, "What ethical principles should guide the practice of newborn screening in the United States?" The Council identified seven elements that should be part of "an ethically sound approach to public policy in newborn screening."

SACHDNC discusses each of these elements, from an historical overview of the guiding principles used by newborn screening programs to the current state of newborn screening in the United States.

\section{ELEMENTS 1 AND 2}

- Reaffirm the essential validity and continuing relevance of the classical Wilson-Jungner screening criteria.

- Insist that mandatory newborn screening be recommended to the states only for those disorders that clearly meet the classical criteria.

Over the past 4 decades, newborn screening policies have been guided by principles presented in a 1968 World Health Organization monograph entitled Principles and practice of 
screening for disease by Wilson and Jungner ${ }^{3}$ and by the principles set forth in the 1975 report, Genetic Screening, from the National Research Council (NRC) of the National Academy of Sciences (NAS). ${ }^{4}$

In their monograph, Wilson and Jungner identified 10 criteria for including a condition in a population-screening program. Although designed for the screening of adult-onset chronic diseases and not specifically designed for newborn and pediatric screening, these criteria have been applied to newborn screening programs. There are generally three prime and commonly cited Wilson and Jungner criteria: a specific and sensitive screening test, a sufficiently well-understood natural history, and an available and efficacious treatment. The Council has taken the view that "available and efficacious treatment" represents direct medical therapy and that only the Wilson and Jungner criteria should provide the guiding principles for mandated newborn screening. Although the Council neither endorsed nor rejected the current list of recommended core conditions, they did express concern that some components of the core panel may not meet Wilson and Jungner criteria and that the evidence base for decision making may not be in place to evaluate possible new additions to the recommended panel. The Council pointed to the lack of randomized controlled trials for the evaluation of the treatments for some of the conditions. However, they acknowledged arguments on both sides of that concern and focused on two issues: the American College of Medical Genetics (ACMG) Expert Panel's use of a "broadened concept of benefit" and the Expert Panel's readiness to allow progress in "multiplex screening technology" to dictate the pace and scope of newborn screening. They did not discuss the criteria proposed by the NAS in 1975 for newborn screening programs. The SACHDNC thinks that the core conditions in the Recommended Uniform Screening Panel do meet the Wilson and Jungner criteria.

\section{THE QUESTION OF BENEFIT}

In 2002, an expert group commissioned by the US Health Resources and Services Administration was assembled by the ACMG to evaluate conditions for inclusion in the uniform screening panel. The ACMG expert group's report and recommendations for a core panel and secondary targets were endorsed by SACHDNC, the American Academy of Pediatrics, the March of Dimes, and other organizations.

The ACMG expert group initially developed a set of principles to guide its evaluation and recommendation processes. The ACMG group began with the principle that newborn screening policy development should be primarily driven by what is in the best interest of the affected newborn. The ACMG process adhered to the Wilson and Jungner and NAS/NRC criteria, and conditions were assessed on the availability of a specific and sensitive screening test, a sufficiently understood natural history, and an available and efficacious treatment. The deliberations of ACMG expert group resulted in a 2005 report that recommended mandatory newborn screening for a core panel of 29 disorders. ${ }^{5}$ This core panel is aligned with the Wilson and Jungner criteria. However, inclusion of the secondary targets in the ACMG recommendations ushered in a broader concept of benefit. The ACMG expert group considered the NAS/NRC criteria when developing its framework for the secondary targets. The NAS/NRC criteria were aligned with the Wilson and Jungner criteria, but the NAS/NRC report noted that genetic screening might be appropriate even when a direct medical treatment is not available if there is benefit to the infant to provide management and support, to the family to inform sub- sequent reproductive decision, and to society to provide knowledge about the condition.

In its report, the Council acknowledged that the ACMG expert group's decisions were "fairly consonant with accepted screening principles" but disapproved of the group's decision framework that gave consideration of benefits to family and society. The Council was particularly concerned that the ACMG expert panel principle of benefit allows for the inclusion in a uniform newborn screening panel of a large set of poorly understood conditions for which no proven treatment is available. They felt that there were conditions added to the ACMG screening panel, specifically the conditions in the secondary target category, which failed to meet the traditional criteria. As per the Council, these secondary conditions were included under "an expanded conception of benefit that included not only helping the family avoid 'the diagnostic odyssey' but also helping society by providing opportunities for biomedical research aimed at understanding the natural history of the disorder and finding effective treatment for it."

However, the ACMG expert group began with the understanding that rather than screening for the conditions categorized as secondary targets, the secondary targets were revealed by the screening technology or secondary to the diagnostic process. They determined that it was basically unfair not to reveal knowledge to the parent if early identification of an infant with a condition could be beneficial to the infant, to his/her family, and/or society even beyond direct medical treatment. When considering the secondary targets, it was noted by the ACMG expert group that the infant could benefit from an early diagnosis and early intervention and that their families could benefit from the knowledge that there may be a genetic risk of disease to other members of the family. Society could benefit from a reduction in medical diagnostic odysseys that are costly to the healthcare system and very difficult on the family and child. The benefit of opportunity for research studies was not part of the ACMG's criteria for either the core panel or secondary targets.

In addition, the Council's conclusions are based on a mischaracterization of the recommendations from the ACMG expert panel and indicates that the ACMG expert panel recommended "mandatory screening for twenty-five secondary conditions" that did not meet the criteria for inclusion in the panel of core conditions. However, the ACMG expert panel indicates that States should screen for all specified core panel conditions and report all secondary target conditions and any abnormal results that may be associated with clinically significant conditions, not mandate screening for these secondary targets. The secondary target category includes conditions that are already part of the differential diagnosis of the core panel conditions or are identified (by default) because of analysis or diagnostic evaluation of the bloodspot for a condition on the core panel. Although not part of the ACMG expert panel and SACHDNC rationale for the recommendations, inclusion in the secondary target category also allows for the collection of cases on a national level for further investigation to understand the disease process and for the development of treatment modalities. Therefore, a clear distinction needs to be made between these core conditions recommended for mandatory screening and the "secondary" targets that are recommended to be reported. SACHDNC anticipates that other multiplex testing platforms will result in similar secondary findings.

As indicated earlier in the text, SACHDNC has, as one of its charges, the responsibility of making evidence-based recommendations regarding conditions for which newborns and children should be screened as well as evaluating and updating 
SACHDNC's Recommended Uniform Screening Panel. After endorsing the ACMG expert panel report and recommendations in 2005, SACHDNC has developed a prospective process for nomination of additional disorders and evidence review of the appropriateness to include the disorder in the core panel. This process has involved a series of workgroups made up of SACHDNC members and outside experts. These workgroups included Nomination Review and Prioritization; Internal Review; External Evidence Review; and Decision Criteria and Process and have produced a number of reports and two publications. ${ }^{6,7}$ The SACHDNC process builds on the Wilson and Jungner, the NAS/NRC, and the ACMG expert group processes and principles and uses a standardized process for evaluating disorders nominated for inclusion in the Recommended Uniform Screening Panel, weighing the evidence, and gathering input from key stakeholders. Within that evidence-based assessment is the inclusion of families' perspectives on such aspects as the risk or benefit of early diagnosis or the ease or difficulty of treatment.

SACHDNC review uses a number of decision points that include initial review of every nomination to determine whether conditions are amenable for systematic evidence review, review of systematic evidence reviews conducted by the committee's external review group, and deliberation and formal recommendation for adding or exclusion to the uniform recommended panel. Data analyzed include the accuracy and specificity of screening and diagnostic tests for nominated disorders, the extent of predicted health benefits or harms, impact on disease course, and cost from early diagnosis and treatment. ${ }^{7}$ The evidence review process of SACHDNC is guided not only by approaches used by similar entities but also by criteria that accommodate data limitations stemming from the rarity of many of the conditions proposed for screening newborns or children.

\section{ELEMENT 3}

Endorse the view that screening for other conditions that fail to meet the classical criteria may be offered by the states to parents on a voluntary basis under a research paradigm.

The "classical criteria" noted by the Council need to evolve to include the work of the NAS/NRC, the ACMG expert group, and SACHDNC, as clarified in the discussion of the first element. SACHDNC certainly endorses and encourages states to pursue research within the newborn screening programs to enhance screening techniques and study other disorders that may be candidates to join the recommended core panel. Such research should be subject to federal and state research regulation and reviewed by an appropriate institutional review board. Indeed, there are a number of such studies ongoing at this time.

\section{ELEMENT 4}

Affirm when the differential diagnosis of some targeted disorders entails detection of other poorly understood conditions that would not otherwise be suitable candidates for newborn screening, such results need not be transmitted to the child's physician or parents.

The Council concludes that when known, rare, and serious disorders for which treatment is not presently available are found during newborn screening process, states should either suppress the information or develop an informed consent process that is administered at the time of obtaining the newborn screening sample allowing families to opt out of learning about positive results. The Council report does not advocate informed consent for the core conditions, and SACHDNC agrees that informed consent should not be part of newborn screening. However, SACHDNC thinks that an informed consent process designed solely to highlight incidental test results would be confusing to families and potentially harmful to newborn screening public health program in general. SACHDNC does feel that it is important to inform all prospective and new parents about newborn screening, its purpose, and the potential for some children to need confirmatory testing if the results are positive.

In addition, SACHDNC thinks that there are a number of reasons to inform a family of incidental findings from mandated newborn screening. It again must be emphasized that these incidental findings are inevitable, and the results are an integral part of the testing process. These results are in the hands of the state because of testing for the core panel. Important and appropriate reasons for revealing these findings to families include the following:

1. Avoid the agonizing and expensive "diagnostic odyssey."

2. Inform future reproductive decision making.

3. Inform management decisions for the infant.

4. Provide early supportive intervention for the child and family.

5. Clinical research studies may be available to the family.

6. It is inherently unfair to withhold these results.

A pivotal point of SACHDNC departure from the Council's conclusions may be around the issue of "fairness." Consider the family who learns that the state newborn screening program knew about a serious disorder days after their child was born and refrained from telling them. This family might rightly consider this unfair to them and their family and have the expectation that the state would have shared such information preventing them from the emotional and financial hardship of learning about their child's diagnosis over the first year of life. This revealing of incidental findings does not require prospective informed consent but rather informing all families that this may occur in the educational materials that are provided before or at the time of birth. Reasonable people would wish to know and would expect the state to inform them about their child's condition.

\section{ELEMENT 5}

Encourage the states to reach a consensus on a uniform panel of conditions clearly meriting mandatory screening.

SACHDNC agrees that there should be a uniform panel of core conditions that all states adopt. SACHDNC was chartered in 2003 to advise the Secretary, HHS, regarding the application of newborn screening and develop policies and guidelines toward that end. A national review process is needed because no individual state has the expertise alone to evaluate all these rare conditions. When adopting SCID for the Recommended Uniform Screening Panel, the Secretary, HHS, noted the she was adopting this panel "as a national standard for newborn screening programs" and that she would "facilitate the adoption of the SACHDNC's Recommended Uniform Screening Panel by all State newborn screening programs."

\section{ELEMENT 6}

Urge a thorough and continuing reevaluation of the disorders now recommended for inclusion in the mandatory screening panel, to ascertain whether they genuinely meet the classical 
criteria that would justify mandatory screening of all newborns or whether they instead are suitable candidates for pilot screening studies.

Continual evaluation of the national newborn screening program to assure clinical effectiveness of this public health effort is certainly warranted and ongoing by SACHDNC.

\section{ELEMENT 7}

Reject any simple application of the "technological imperative," i.e., the view that screening for a disorder is justified by the mere fact that it is detectable by multiplex assay, even if the disorder is poorly understood and has no established treatment.

SACHDNC agrees that it is unwise simply to adopt a technological imperative in planning the expansion of the newborn or any screening program. If all other criteria are met, SACHDNC review process looks at technology to answer three questions:

1. Is a suitable test available?

2. Can that testing method meet national public health needs?

3. Is the test economically feasible?

\section{CONCLUSION}

Newborn screening is an established state-based public health program that is extremely effective and a model for early diagnosis and treatment. SACHDNC offers guidance to public health and healthcare professional and the public through its recommendations to the Secretary, HHS.

SACHDNC has moved well beyond the seven elements noted in the Council on Bioethics report. SACHDNC's structured evidence-based assessment of nominated conditions supports a consistently rigorous, iterative, and transparent approach to its making recommendations regarding broad populationbased screening programs for rare conditions in infants and children. ${ }^{7}$

\section{REFERENCES}

1. The President's Council on Bioethics, 2008. Available at: http://www.bioethics. gov/reports/newborn_screening/index.html. Accessed November 19, 2010.

2. Fleischman AR, Lin BK, Howse JL. A commentary on the President's Council on Bioethics report: the changing moral focus of newborn screening. Genet Med 2009;11:507-509.

3. Wilson JMG, Jungner G. Principles and practice of screening for disease. Geneva: World Health Organization, 1968. Available at: http://www.who.int/ bulletin/volumes/86/4/07-050112BP.pdf. Accessed July 4, 2009.

4. Genetic screening: programs, principles and research. National Research Council, Committee for the Study of Inborn Errors of Metabolism. Washington, DC: National Academy of Sciences, 1975.

5. Newborn screening: toward a uniform screening panel and system. Genet Med 2006;8(suppl 1):1S-252S.

6. Green NS, Rinaldo P, Brower A, et al. Committee report: advancing the current recommended panel of conditions for newborn screening. Genet Med 2007;9:792-796.

7. Calonge N, Green NS, Rinaldo P, et al. Committee report: method for evaluating conditions nominated for population-based screening of newborns and children. Genet Med 2010;12:153-159. 